\title{
SISTEM INFORMASI PERSEDIAAN BARANG PADA TOKO MAINAN NANDA TOYS BEKASI
}

\author{
Annisa Rizki ${ }^{1}$ \\ Sistem Informasi \\ Universitas Bina Sarana Informatika \\ annisarizki06@gmail.com
}

\author{
Anna Mukhayaroh ${ }^{2}$ \\ Sistem Informasi \\ STMIK Nusa Mandiri Jakarta \\ anna.auh@nusamandiri.ac.id
}

\author{
Erene Gernaria Sihombing ${ }^{3}$ \\ Sistem Informasi \\ STMIK Nusa Mandiri Jakarta \\ erene.egs@nusamandiri.ac.id
}

\begin{abstract}
Abstrak - Sistem persediaan adalah suatu proses yang menentukan dan mengelola informasi tentang persediaan yang ada dalam suatu perusahaan. Saat ini bagian persediaan pada Toko Nanda Toys Bekasi masih mengelola data persediaan barang dengan menggunakan sistem konvensional. Dengan sistem seperti itu menyebabkan sering terjadinya kesalahankesalahan yang dapat berdampak pada persediaan barang secara keseluruhan. Penggunaan sistem informasi berbasis komputer adalah jawaban dari permasalahan-permasalahan yang ada. Dengan dibangunnya sistem informasi persediaan akan membantu proses pemesanan, masuknya barang, keluarnya barang, retur barang supaya lebih efektif dan efisien dan menghasilkan informasi laporan-laporan yang cepat dan akurat serta meminimalkan kesalahan yang mungkin terjadi.
\end{abstract}

Kata kunci : Sistem Informasi, Persediaan Barang

\section{PENDAhuluan}

Perusahaan senantiasa memberi perhatian yang besar pada persediaan karena apabila tanpa persediaan, para pengusaha akan berhadapan dengan resiko bahwa perusahaannya pada suatu waktu tidak dapat memenuhi keinginan para pelanggannya. Toko Nanda Toys merupakan salah satu perusahaan yang bergerak dibidang usaha penjualan yang menjual berbagai macam mainan untuk balita dan anak-anak. Dalam melakukan kegiatan usahanya, khususnya dalam pengolahan data persediaan masih menggunakan sistem konvensional dari proses pengecekan stok barang, proses pembuatan daftar barang yang harus dibeli, proses penerimaan barang sampai pembuatan laporan. Dikarenakan masih menggunakan sistem konvensional menimbulkan beberapa masalah seperti lamanya proses pengecekan stok barang yang kosong karena harus mengecek dan mencari barang apa yang kosong, karena tidak ada catatan data barang yang keluar dari gudang, sering terjadi hilang nota transaksi pembelian barang, yang merupakan bukti dari setiap transaksi pembelian yang dilakukan dan data barang yang masuk. Nota pembelian tersebut juga merupakan data yang diperlukan untuk proses pembuatan laporan pembelian, dimana proses pembuatan laporan pembelian masih harus menghitung dengan menggunakan kalkulator setiap nota yang ada. Sehingga mengakibatkan pembuatan laporan yang tidak akurat dan relatif lama.

\begin{abstract}
Inventory system is a process that determines and manages information about inventory in a company. Currently the inventory section at the Nanda Toys Bekasi Store still manages inventory data using conventional systems. With such a system it causes frequent errors that can affect the overall inventory. The use of computer-based information systems is the answer to existing problems. With the construction of an inventory information system, it will help the ordering process, the entry of goods, the exit of goods, the return of goods to be more effective and efficient and produce information that reports quickly and accurately and minimizes errors that may occur.
\end{abstract} Keyword : Information System, Inventory

\section{METODE PENELITIAN}

Metode yang digunakan pada pengembangan perangkat lunak ini adalah model prototipe (Prototyping Model). Menurut Sukamto dan M. Shalahudin (2013:31) model prototipe (Prototyping Model) terbagi menjadi 3 tahapan, yaitu:

1. Mendengarkan Pelanggan atau User

Pada tahap ini penulis mengumpulkan kebutuhan dengan menganalisis dan mengetahui terlebih dahulu sistem persedian yang berjalan pada Toko Nanda Toys dan mencari tahu permasalah yang ada.

2. Membangun atau Memperbaiki Mock-up Pada tahap pembuatan desain penulis membuat rancangan sistem usulan mengunakan diagram UML yaitu, use case diagram, activity diagram, sequence diagram dan class diagram, deployment diagram untuk permodelan basis data menggunakan entity relationship diagram dan logical record structure, PhpMyAdmin untuk membuat database, rancangan program prototipe persediaan barang menggunakan aplikasi berbasis desktop VB.Net (Visual Basic. Net).

3. Pelanggan atau User Melihat atau Menguji Mock-up

Pada tahap ini penulis menampilkan program prototipe dengan simulasi alur perangkat lunak serta menjelaskan kepada user kebutuhan 
secara detail melalui program prototipe, diagram UML sampai permodelan basis data dan akan dievaluasi oleh pelangan atau user sampai ditemukan spesifikasi yang sesuai dengan keinginan pelanggan atau user.

Adapun tools system yang digunakan pada penelitian ini, sebagai berikut :

1. UML (Unified Modelling Language)

Menurut Sukamto dan M. Shalahuddin (2013:133) mengemukakan bahwa "UML (Unified Modeling Language) adalah salah standar bahasa yang banyak digunakan di dunia industri untuk mendefinisikan requirement, membuat analisis \& desain, serta menggambarkan arsitektur dalam pemograman berorientasi objek."

Diagram Unified Modeling Language (UML) terdiri dari beberapa diagram, yaitu:

a. Use Case Diagram

Menurut Sukamto dan M. Shalahuddin (2013:155) menyatakan bahwa "Use Case atau diagram use case merupakan permodelan untuk kelakukan (behavior) sistem informasi yang akan dibuat. Use case mendeskripsikan sebuah interaksi antara satu atau lebih aktor dengan sistem informasi yang akan dibuat".

b. Activity Diagram

Menurut Sukamto dan M. Shalahuddin (2013:155) menyatakan bahwa "Diagram aktivitas atau activity diagram menggambarkan workflow (aliran kerja) atau aktivitas dari sebuah sistem atau proses bisnis atau menu yang ada pada perangkat lunak".

c. Sequence Diagram

Menurut Sukamto dan M. Shalahuddin (2013:165) menyatakan bahwa "Diagram sekuen menggambarkan kelakuan objek pada use case dengan mendeskripsikan waktu tempat hidup objek dan message yang dikirimkan dan diterima antar objek".

d. Class Diagram

Menurut Sukamto dan M. Shalahuddin (2013:141) menyatakan bahwa "Diagram kelas atau class diagram menggambarkan struktur sistem dari segi pendefisian kelas-kelas yang akan dibuat untuk membangun sistem".

e. Deployment Diagram

Menurut Sukamto dan M. Shalahuddin (2013:154) menyatakan bahwa "Diagram deployment atau deployment diagram menunjukan konfigurasi komponen dalam proses eksekusi aplikasi”.

\section{ERD (Entity Relationship Diagram)}

Menurut Pratama (2014:49) menyatakan bahwa "ERD (Entity Relationship Diagram) adalah diagram yang menggambarkan keterkaitan antartabel beserta dengan field-field di dalamnya pada suatu database sistem".
Terdapat suatu simbol/notasi dasar yang digunakan pada diagram E-R menurut Priyadi (2014:20), yaitu:

a. Entitas

Entitas merupakan notasi untuk mewakili suatu objek dengan karakteristik sama, yang dilengkapi oleh atribut, sehingga pada suatu lingkungan nyata setiap objek akan berbeda dengan objek lainnya. Pada umumnya, objek dapat berupa benda, pekerjaan, tempat, dan orang.

b. Relasi

Relasi merupakan notasi yang digunakan untuk menghubungkan beberapa entitas berdasarkan fakta pada suatu lingkungan.

c. Atribut

Atribut merupakan notasi yang menjelaskan karakteristik suatu entitas dan relasinya.

d. Garis Penghubung

Garis Penghubung merupakan notasi untuk merangkaikan keterkaitan antara notasi-notasi yang digunakan dalam Diagram E-R, yaitu entitas, relasi, dan atribut.

Kardinalitas Relasi menunjukkan jumlah maksimum entitas yang dapat berelasi dengan entitas pada himpunan entitas lainnya. Kardinalitas Relasi yang terjadi diantara dua himpunan entitas (misalnya A dan B) menurut Fathansyah (2015:79), yaitu:

a. $\quad$ Satu ke Satu (One to One)

Yang berarti setiap entitas pada himpunan entitas A berhubungan dengan paling banyak dengan satu entitas pada himpunan entitas B, dan begitu juga sebaliknya setiap entitas pada himpunan entitas B berhubungan dengan paling banyak dengan satu entitas pada himpunan A.

b. $\quad$ Satu ke Banyak (One to Many)

Yang berarti setiap entitas pada himpunan A dapat berhubungan banyak entitas pada himpunan entitas B, tetapi tidak sebaliknya, dimana setiap entitas pada himpunan B berhubungan paling banyak dengan satu entitas pada himpunan entitas A.

c. Banyak ke Satu (Many to One)

Yang berarti setiap entitas pada himpunan entitas A berhubungan dengan paling banyak dengan satu entitas pada himpunan entitas B, tetapi tidak sebaliknya, dimana setiap entitas pada himpunan A berhubungan dengan paling banyak satu entititas pada himpunan entitas B.

d. Banyak ke Banyak (Many to Many)

Yang berarti setiap entitas pada himpunan entitas A dapat berhubungan dengan banyak entitas pada himpunan entitas B, dan demikian juga sebaliknya, di mana setiap entitas pada himpunan entitas B dapat berhubungan dengan banyak entitas pada himpunan entitas A. 
3. LRS (Logical Relationship Structure)

Menurut Hasugian dan Shidiq dalam Larasati dan Masripah (2017:194) memberikan batasan bahwa "Logical Record Struktured (LRS) adalah sebuah model sistem yang digambarkan dengan sebuah diagram-ER akan mengikuti pola atau aturan permodelan tertentu dalam kaitannya dengan konvensi ke LRS”.

\section{PEMBAHASAN}

\subsection{Tahapan Perancangan Sistem}

Terdapat beberapa tahapan dalam perancangan sistem, yaitu :

\section{Analisa Kebutuhan}

Dalam program persediaan barang pada Toko Nanda Toys ini terdapat dua pengguna yang saling berinteraksi dalam lingkungan sistem, yaitu bagian gudang dan pemilik toko. Kedua penguna ini memiliki karakteristik interaksi dengan sistem yang berbeda dan memiliki kebutuhan informasi yang berbeda, seperti berikut:

Skenario Kebutuhan Bagian Gudang

A1. Dapat melakukan login.

A2. Mengelola data supplier.

A3. Mengelola data barang.

A4. Mengelola data pemesanan.

A5. Mengelolah data barang masuk.

A6. Mengelola data barang keluar.

A7. Mengelola data retur barang.

A8. Mencetak laporan data supplier.

A9. Mencetak laporan data barang

A10. Mencetak laporan pemesanan.

A11. Mencetak laporan barang masuk.

A12. Mencetak laporan barang keluar.

A13. Mencetak laporan retur barang

A14. Dapat mengubah password.

A15. Dapat melakukan logout.

2. Skenario Kebutuhan Pemilik Toko

B1. Dapat melakukan login.

B2. Mengolah data pengguna.

B3. Mencetak laporan data supplier.

B4. Mencetak laporan data barang.

B5. Mencetak laporan pemesanan.

B6. Mencetak laporan barang masuk.

B7. Mencetak laporan barang keluar.

B8. Mencetak laporan retur barang

B9. Dapat mengubah password.

B10. Dapat melakukan logout.

3. Kebutuhan Sistem

a) Untuk dapat mengakses program ini, pengguna harus melakukan login terlebih dahulu dengan memasukkan kode pengguna dan password agar masing-masing pengguna agar tetap terjaga keamanannya.

b) Setelah selesai menggunakan program, pengguna harus melakukan logout agar tetap terjaga keamanannya.

c) Sistem melakukan kalkulasi stok barang. d) Sistem melakukan kalkulasi data pemesanan, data barang masuk, barang retur dan barang keluar.

\subsection{Desain Sistem dengan UML}

Diagram use case menunjukan interaksi antara usecase dan actor.

\section{Use Case Diagram Bagian Gudang}

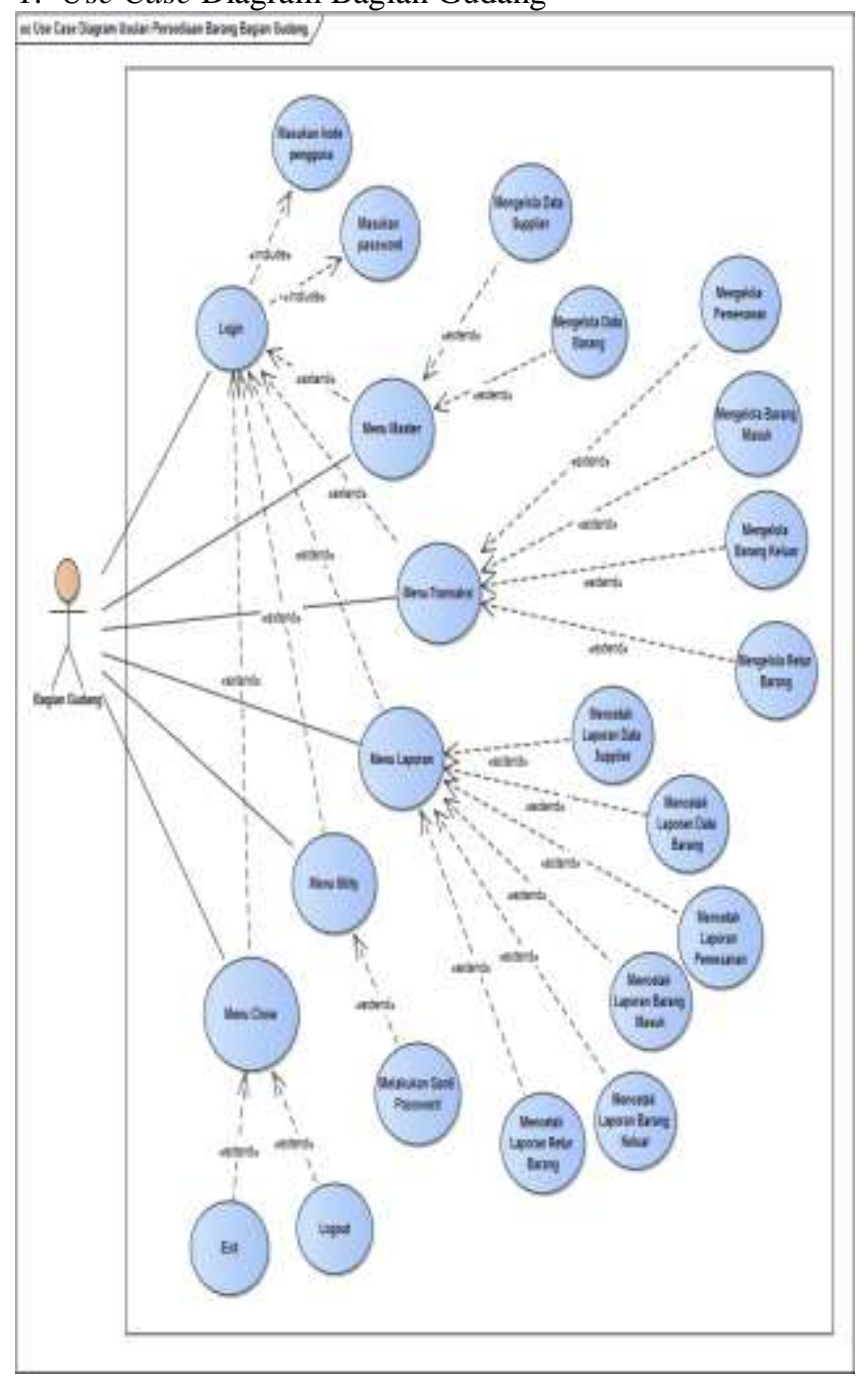


2. Use Case Diagram Pemilik

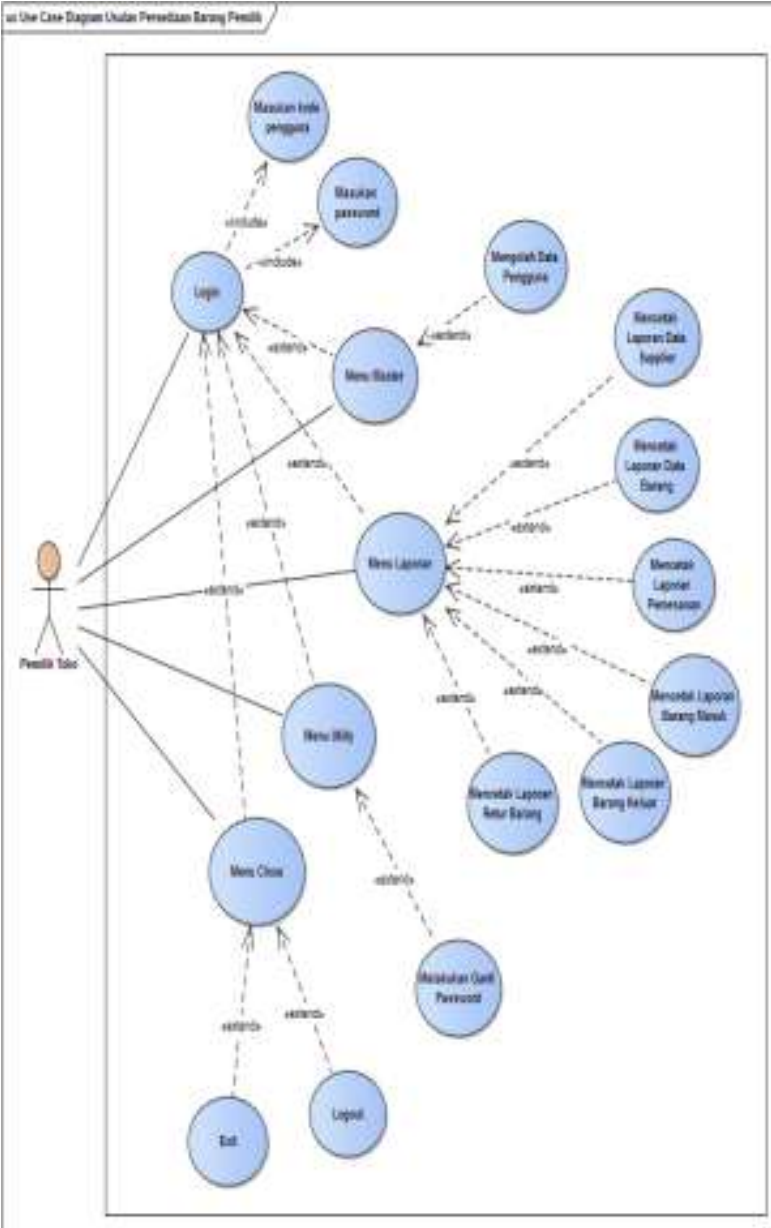

\subsection{Activity Diagram}

1. Activity Diagram Login Bagian Gudang

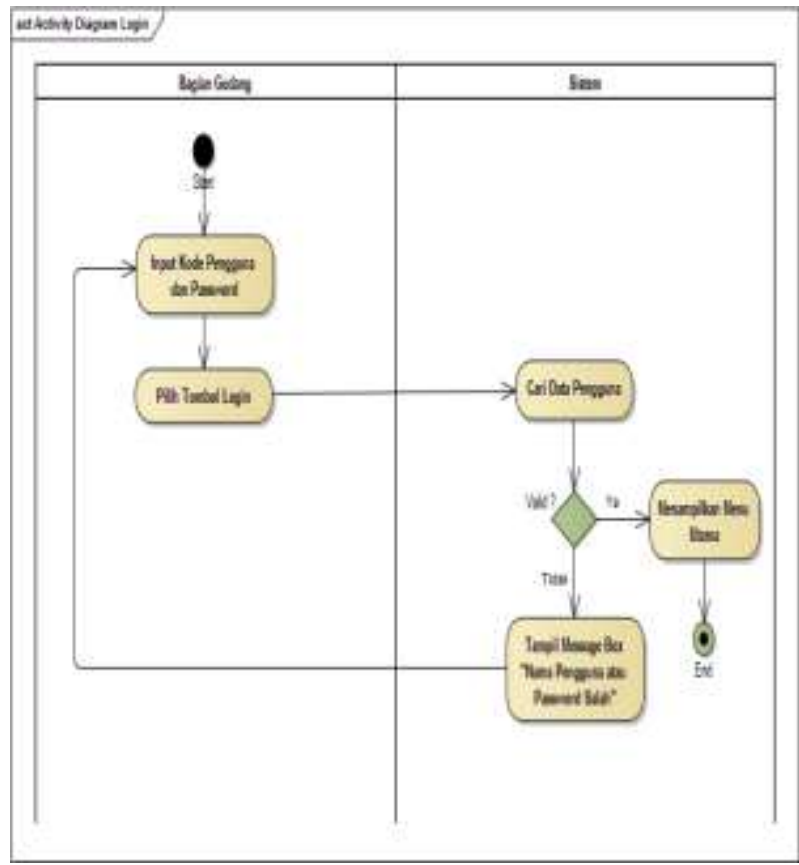

2. Activity Diagram Mengelola Data Supplier 

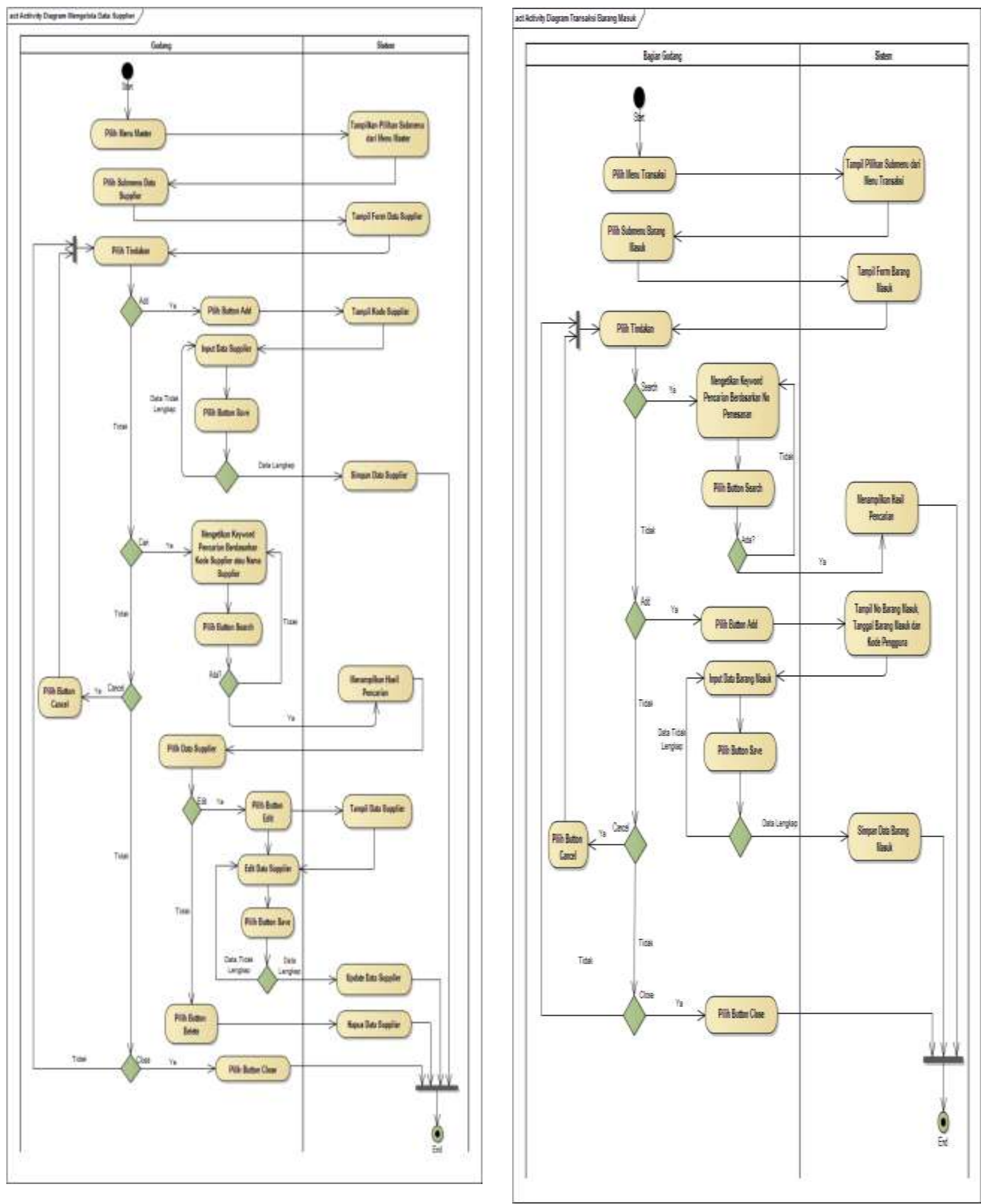

3. Activity Diagram Mengelola Transaksi Barang Masuk 
4. Activity Diagram Mengelola Transaksi Barang Keluar

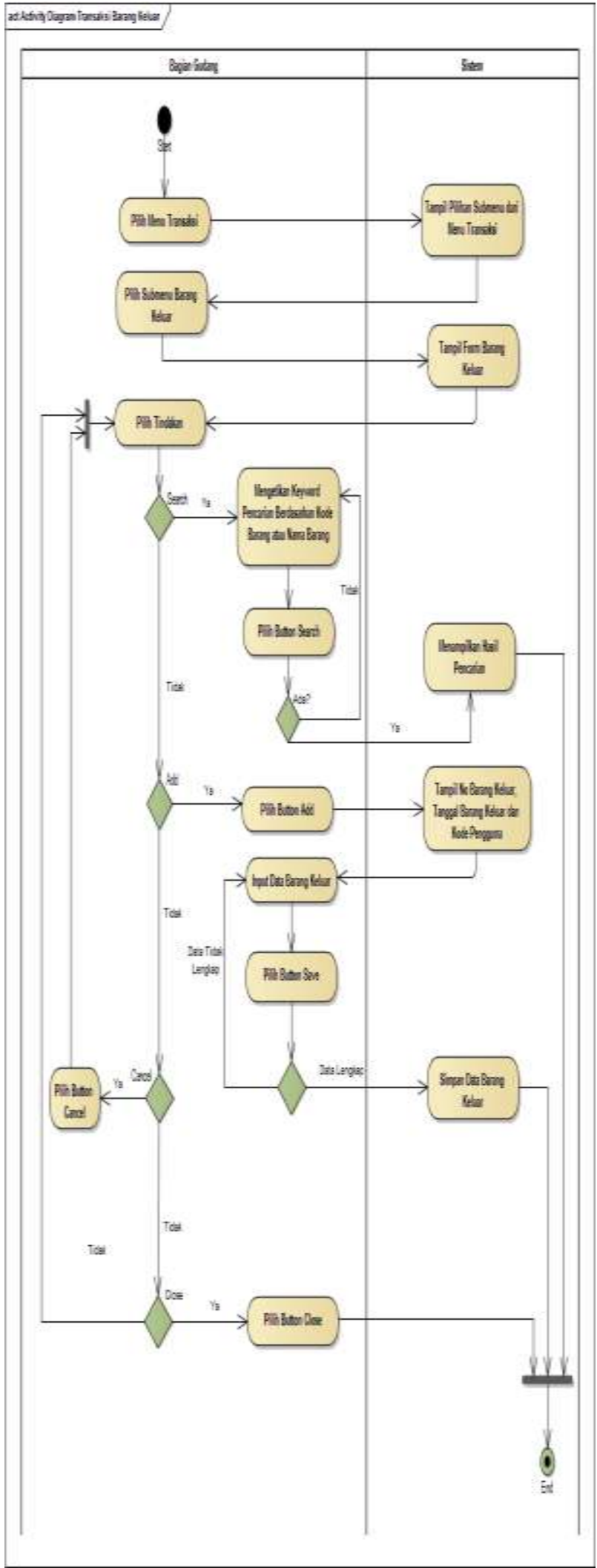

5. Activity Diagram Mengelola Transaksi Retur Barang

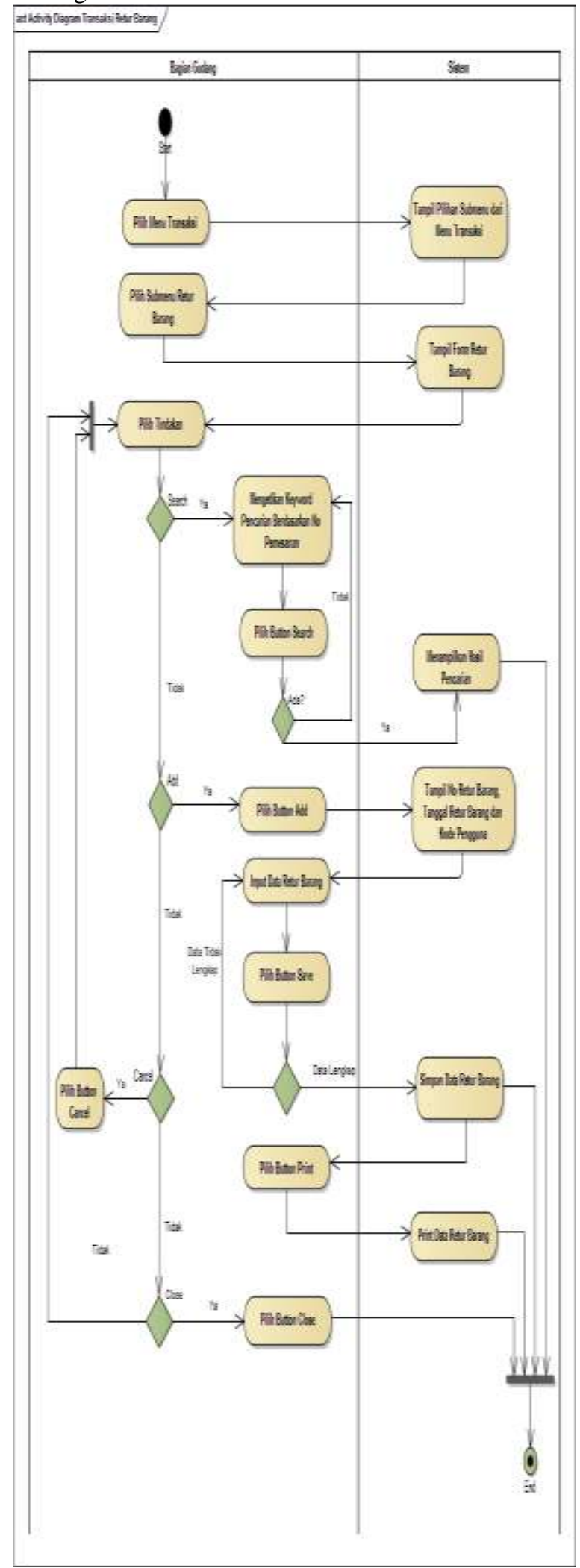


6. Activity Diagram Bagian Gudang Mencetak Laporan Retur

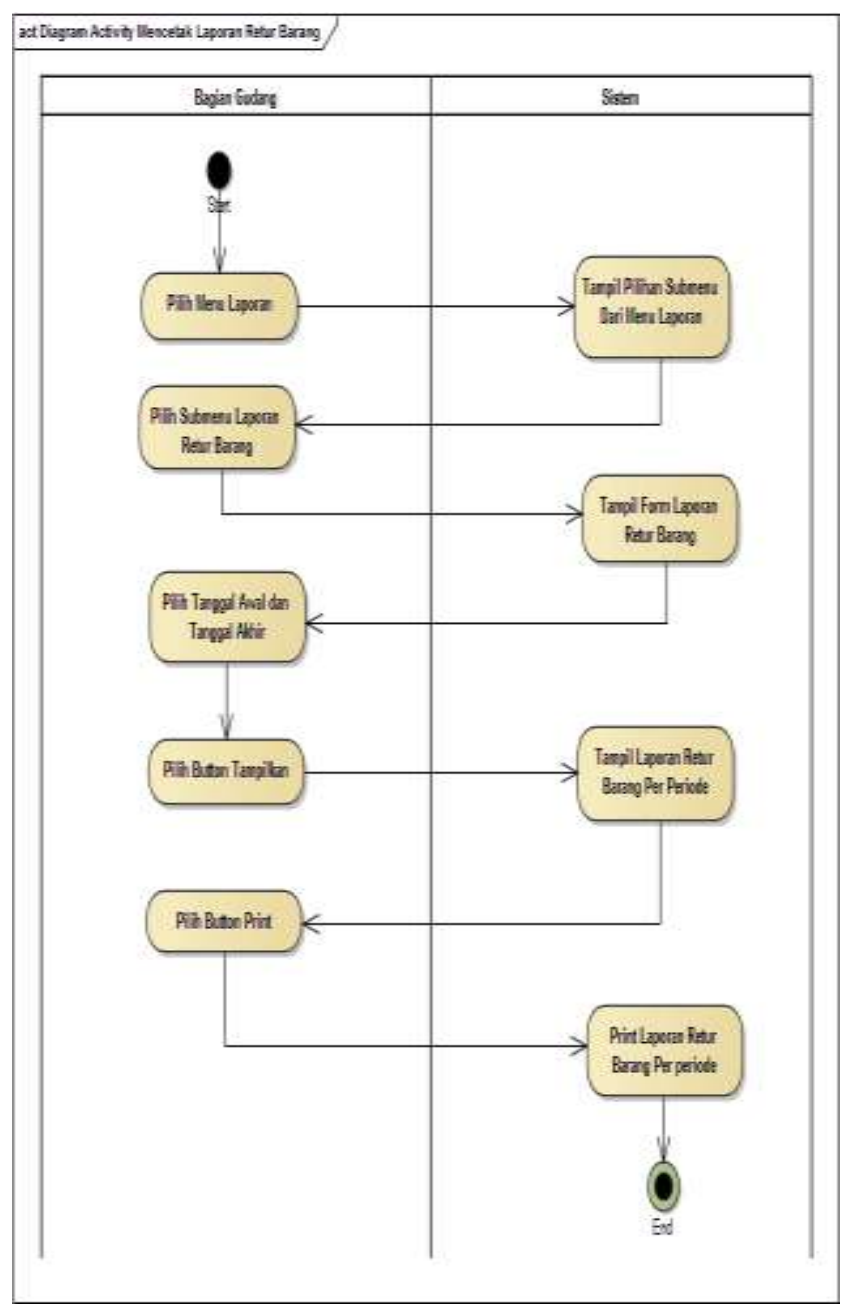

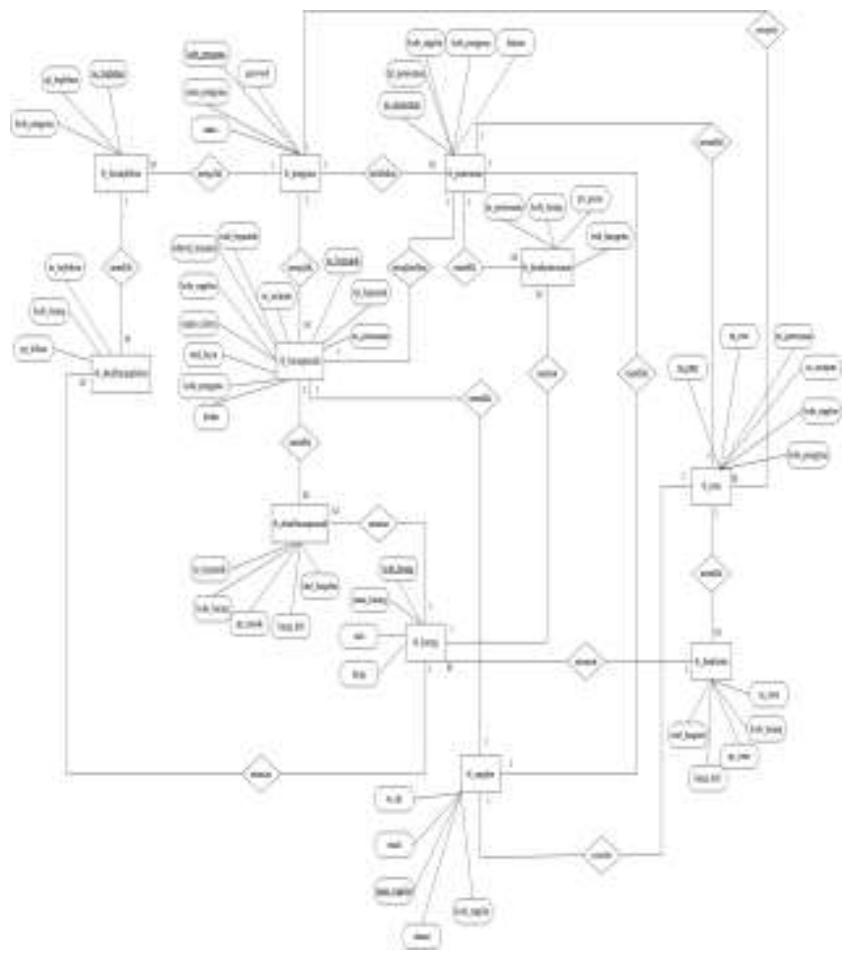

3.5. Logical Record Structure

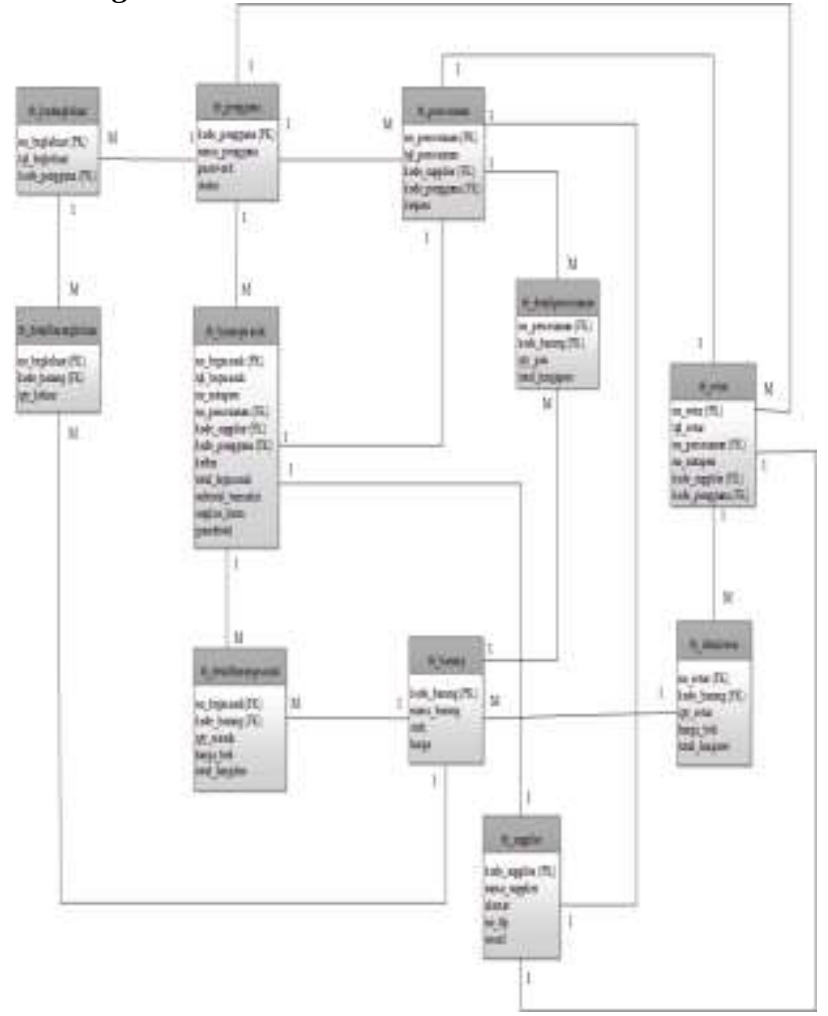




\section{HASIL TAMPILAN ANTARMUKA}

1. Form Login

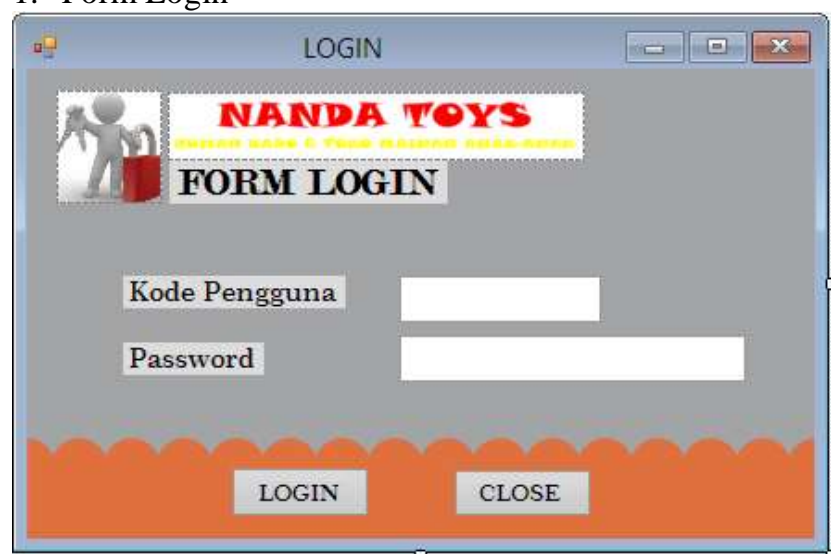

2. Form Menu Utama

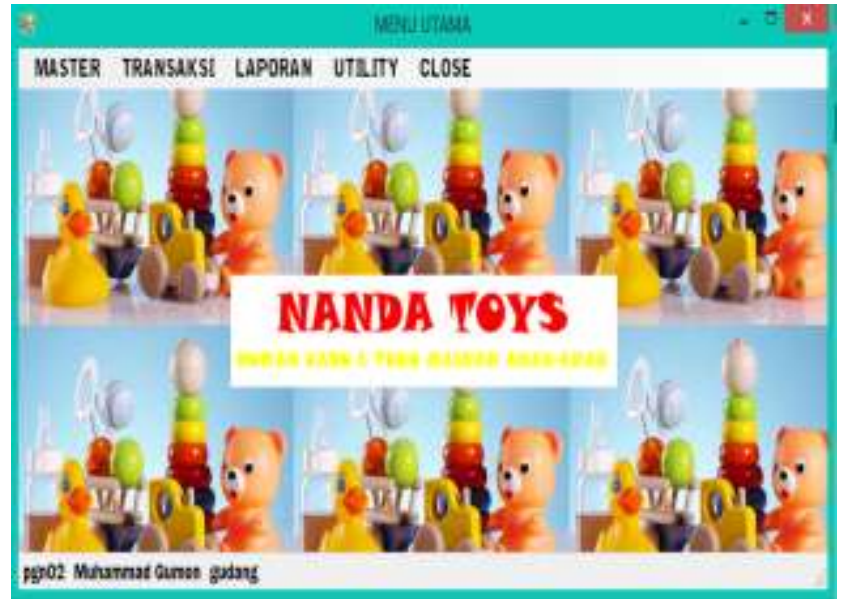

3. Form Master Data Supplier

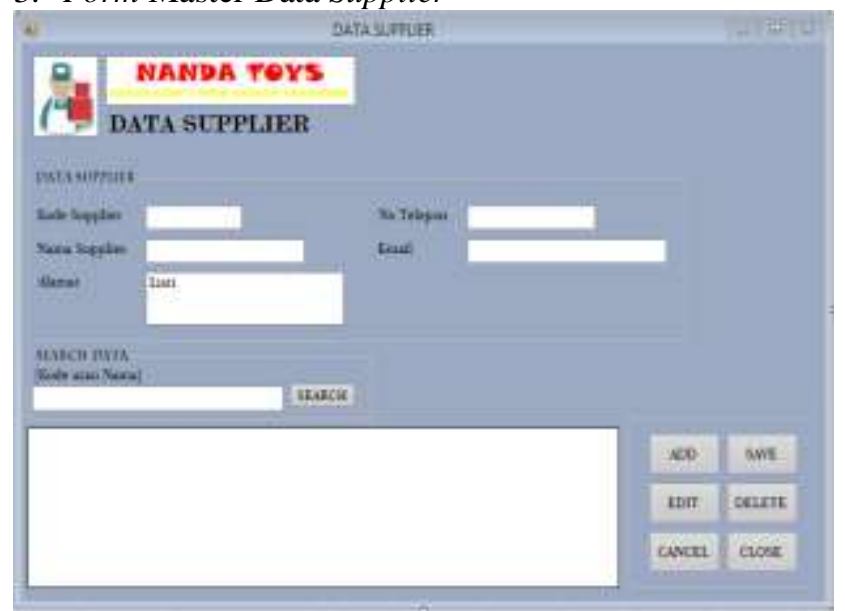

4. Form Transaksi Barang Masuk

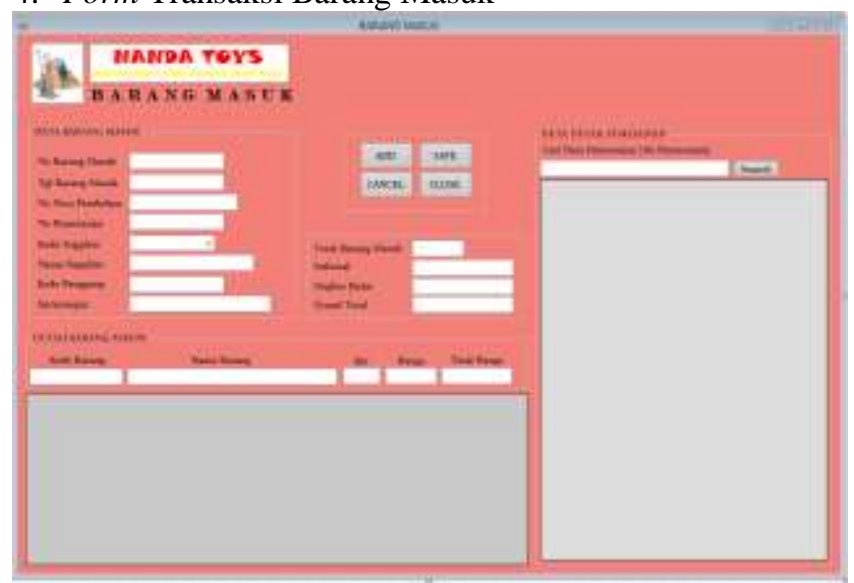

5. Form Laporan Barang Masuk

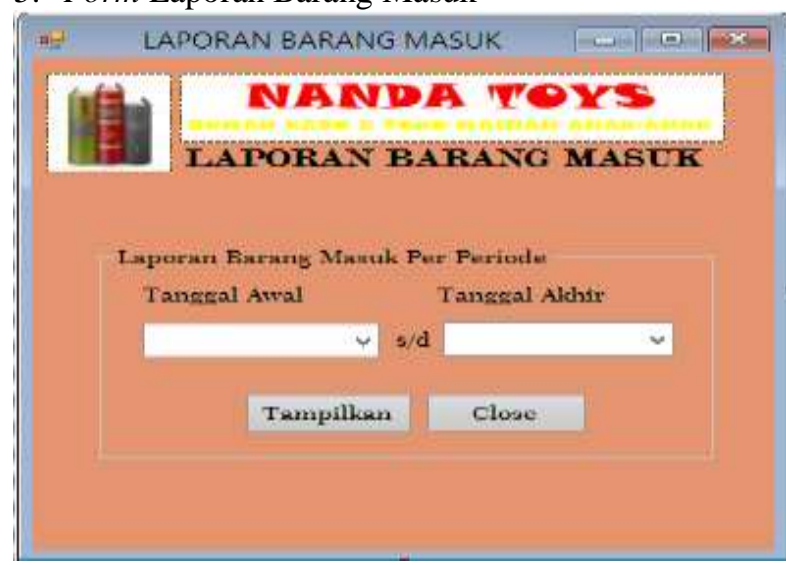

6. Form Ganti Password

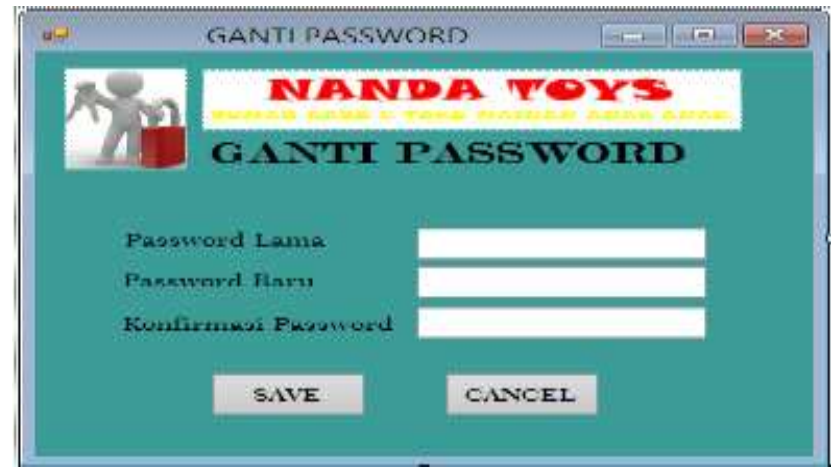

\section{KESIMPULAN}

1. Sistem yang masih konvensional dalam pengolahan data dan proses pengecekan stok barang sampai pembuatan laporan dirasakan kurang efektif dan efisien, maka penulis menyarankan pemakaian sistem yang sudah terkomputerisasi.

2. Dengan sistem informasi persediaan barang yang telah terkomputerisasi tentunya akan mempermudah bagian gudang dan pemilik Toko dalam mengelola transaksi barang masuk, transaksi barang keluar dan retur barang.

3. Sistem persediaan barang yang telah terkomputerisasi dengan menggunakan program persediaan barang dapat memudahkan 
dalam pembuatan laporan- laporan dan dapat menghemat waktu dalam proses perhitungan sehingga laporan yang dihasilkan lebih akurat.

4. Melalui Sistem persediaan barang yang telah terkomputerisasi ini penyimpanan data dapat lebih terorganisir, menghemat waktu, dan memudahkan pencarian data.

\section{REFERENSI}

Fathansyah. (2015). Basis Data Revisi Kedua. Bandung: Informatika Bandung.

Larasati, H., \& Masripah, S. (2017). Analisa Dan Perancangan Sistem Informasi Pembelian GRC Dengan Metode Waterfall. Jurnal Pilar Nusa Mandiri, 193-198.

Pratama, E. (2014). Sistem Informasi Dan

Implementasinya. Bandung: Informatika Bandung.

Priyadi, Y. (2014). Kolaborasi SQL \& ERD Dalam Implementasi Database. Yogyakarta: CV. Andi Offset.

Sukamto, R., \& M. Shalahuddin. (2013). Rekayasa Perangkat Lunak Terstruktur Dan Berorientasi Objek. Bandung: Informatika Bandung. 